\title{
As Políticas Educacionais e a Interface Neoliberal: A educação como um "Tesouro a descobrir"
}

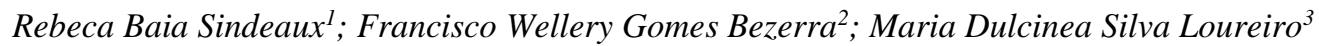

\begin{abstract}
Resumo: Partindo da premissa de que o capitalismo tem a capacidade de, em momentos de crise, se erguer com mais força, este artigo se dispôs a analisar em que medida a crise contemporânea interfere na implantação de políticas educacionais na periferia do capital. Para garantir o processo de reestruturação os capitalistas recorreram às políticas neoliberais, em que se exigia um tipo de trabalhador que atendesse as novas demandas produtivas. Neste cenário contemporâneo de crise, as determinações oriundas da agenda do capital internacional para educação, mais especificamente formuladas a partir de 1990 pela Conferência Mundial de Educação para Todos, patrocinada pelo Banco Mundial, podem ser consideradas como o marco na busca pelo ajuste da educação às necessidades do mercado, diante de um processo de reestruturação produtiva. Esse artigo faz uma revisão de literatura de obras que tratam dos impactos pós Conferência Mundial de Educação Para Todos na educação dos países da periferia do capital. As considerações deste artigo apontam para uma reflexão sobre como a "desejada" redução do Estado passa necessariamente pela conversão da Educação de um direito social a um serviço, o que atende aos interesses do capital financeiro como estratégia política de manutenção de um modo de produção pautado no consumo.
\end{abstract}

Palavras-chave: Educação. Crise. Neoliberalismo.

\section{Educational Policies and the Neoliberal Interface: Education as a "Treasure to be Discover"}

\begin{abstract}
Starting from the premise that capitalism has the capacity to rise more strongly in times of crisis, this article prepared to analyze the extent to which the contemporary crisis interferes with the implementation of educational policies in the periphery of capital. To guarantee the restructuring process, the capitalists resorted to neoliberal policies, in which a type of worker was demanded to meet the new productive demands. In this contemporary crisis scenario, determinations from the international capital agenda for education, more specifically formulated since 1990 by the World Bank-sponsored World Conference on Education for All, can be considered as the milestone in in the face of a process of productive restructuring. This article reviews the literature on works that deal with the post-World Conference on Education for All impacts on the education of countries on the periphery of capital. The considerations of this article point to a reflection on how the "desired" reduction of the State necessarily passes through the conversion of Education from a social right to a service, which serves the interests of financial capital as a political strategy to maintain a mode of production ruled in consumption.
\end{abstract}

Keywords: Education. Crisis. Neoliberalism.

\footnotetext{
${ }^{1}$ Graduada em Pedagogia pela Universidade Estadual do Ceará - UECE. Especialista em Gestão Escola pela Universidade Estadual do Ceará - UECE. Mestranda em Educação, Universidade Regional do Cariri - URCA.

rebeca.baia.sindeaux@gmail.com;

${ }^{2}$ Graduado em Ciências Sociais. Especialista em Ensino de Sociologia. Mestrando em Educação pela Universidade Regional do Cariri - URCA. wellerygomes@gmail.com;

${ }^{3}$ Orientadora. Professora Doutora do curso de Pedagogia e do Mestrado Profissional em Educação da Universidade Regional do Cariri - URCA. dulcinea.loureiro@ urca.br.
} 


\title{
Introdução
}

O presente artigo é fruto de um estudo bibliográfico, gestado na disciplina "História da Educação Brasileira", e tem a proposta de analisar a crise contemporânea do capitalismo e as suas manobras de regulação social do Estado pela Educação, mediante contexto de expansão e consolidação da mercantilização do ensino. Saviani (2008) vem denominar esse momento histórico educacional de "O neoprodutivismo e suas variantes: neo-escolanovismo, neoconstrutivismo, neotecnicismo" (p. 425) no qual destacaremos o lema "aprender a aprender”. As análises remetem à discussão sobre a Conferência Mundial de Educação, posto que a consideramos um marco referencial para a implementação das políticas neoliberais em relação à educação nos países da periferia do capital.

Em decorrência da crise de 1970 (MÉSZÁROS, 2000), o Estado passa a "trabalhar" para as grandes corporações, fazendo das escolas e universidade locais de desenvolvimento de competências e habilidades necessárias "ao tipo de sociedade decorrente da reorganização do processo produtivo" (SAVIANI, 2008, p.438) com o objetivo de garantir mão de obra qualificada/barata para atender as demandas do mercado. Nessa perspectiva “o aprender a aprender" premissa da escola nova, aparece como uma nova roupagem como salienta Saviani (2008),

\begin{abstract}
A pedagogia das competências apresenta-se como outra face da pedagogia do 'aprender a aprender', cujo objetivo é dotar os indivíduos de comportamentos flexíveis que lhes permitam ajustar-se às condições de uma sociedade em que as próprias necessidades de sobrevivência não estão garantidas. Sua satisfação deixou de ser um compromisso coletivo, ficando sob a responsabilidade dos próprios sujeitos que segundo a raiz etimológica dessa palavra, se encontram subjugadas à mão invisível do mercado $(2007$, p. 435).
\end{abstract}

Diante disso, pode-se averiguar que a educação, torna-se terreno propício para restruturação do capital na medida em que são incorporadas ações do Estado sob orientação dos organismos internacionais, visto que "as novas lógicas requerem trabalhadores e consumidores mais formados e qualificados, quer para produzirem mercadorias ou serviços, quer para utilizálos" (CHARLOT, 2014, p. 20). E para isso as empresas buscam "substituir o conceito de qualidade pelo de competência" (SAVIANI, 2008, p. 438). 
Saviani (2008) nos auxilia a pensar o que se constitui a premissa do "aprender a aprender", criticando a forma como a escola, no contexto de formação de capital humano ${ }^{4}$ passa a ser o parâmetro que define a educação em vários países, incluindo o Brasil.

Assim, podemos analisar de que forma esses fenômenos direcionam a educação brasileira e a Lei de Diretrizes e Bases do ano de 1996. Onde suas bases fundamentais estão pautadas na Constituição Federal de 1988, “visando garantir o mínimo necessário para atenuar a disparidade nos recursos entre Estados e Municípios" (ANDRADE et al. 2016, p. 447).

\title{
A Crise do Capital, o Neoliberalismo e a Educação
}

Vivenciamos os entraves de uma crise que, para Meszáros (2000), configura-se como estrutural por resultar do encontro do capital com suas próprias contradições, logo "[...] não estamos frente a uma crise cíclica do capitalismo mais ou menos extensa, como as vividas no passado, mas a uma crise estrutural, profunda, do próprio sistema do capital” (Idem, p.7). E como desdobramentos esta crise afeta o conjunto da humanidade, “[...] exigindo, para esta sobreviver, algumas mudanças fundamentais na maneira pela qual o metabolismo social é controlado" (Idem, ibidem). Destarte, “a crise estrutural do capital é a séria manifestação do encontro do sistema com seus próprios limites intrínsecos” (Idem, p.14).

Acerca das características da crise estrutural, anuncia ainda Antunes:

\begin{abstract}
Hipertrofia da esfera financeira, que ganhava relativa autonomia frente aos capitais produtivos, o que também já era expressão da própria crise estrutural do capital e seu sistema de produção, colocando o capital financeiro como campo prioritário para a especulação, na nova fase do processo de internacionalização; a maior concentração de capitais graças às fusões entre empresas monopolistas e oligopolistas; a crise do welfare state ou do "Estado de bem-estar social" e dos seus mecanismos de funcionamento, acarretando a crise do Estado capitalista e a necessidade de retração dos gastos públicos e sua transferência para o capital privado; incremento acentuado das privatizações, tendência generalizada às desregulamentações e à flexibilização do processo produtivo, dos mercados e da força de trabalho, entre tantos outros elementos contingentes que exprimiam esse novo quadro crítico (1999, p. 30).
\end{abstract}

\footnotetext{
4 "Conceito de capital humano - forjado a partir dos conceitos de capital fixo (maquinaria) e capital variável (salários). O capital humano é o capital incorporado aos seres humanos, especialmente na forma de saúde e educação. (PAIVA, 2001, p.187)
} 
Assim a crise ora anunciada atingiu as estruturas mais profundas do capitalismo e a consequência mais geral tem sido ocasionada na medida em que, para garantir sua reprodução, o capital agravou cada vez mais os problemas sociais, pondo em perigo a existência da própria humanidade (TONET, 2003).

A crise traz diversos impactos no mundo do trabalho, inclusive na formação do trabalhador. Saviani nos ajuda a entender a relação entre a crise e essa formação ao mencionar que,

\begin{abstract}
A crise da sociedade capitalista que eclodiu na década de 1970 conduziu à reestruturação dos processos produtivos, revolucionando a base técnica da produção e conduzindo à substituição do fordismo pelo toyotismo. O modelo fordista apoiavase na instalação de grandes fábricas operando com tecnologia pesada de base fixa, incorporando os métodos tayloristas de racionalização do trabalho; supunha a estabilidade no emprego e visava à produção em série [...] Diversamentente, o modelo toyotista apoia-se em tecnologia leve, de base microeletrônica flexível, e opera com trabalhadores polivalentes visando à produção de objetos diversificados, em pequena escala [...] requer trabalhadores que, em lugar da estabilidade no emprego, disputem diariamente cada posição conquistada, vestindo a camisa da empresa e elevando constantemente sua produtividade. (SAVIANI, 2008, p.429)
\end{abstract}

Nessa conjuntura a educação é pensada numa perspectiva cada vez mais empresarial, ou seja, a educação tecnicista ganha força no modelo educacional empreendedor que transforma o estudante num funcionário habilitado e comprometido, mas pouco reflexivo e muito produtivo.

Constatamos que a atual crise dispõe de artifícios para dar continuidade à reprodução do capital, por intermédio de uma produção extremamente destrutiva (produção de bens supérfluos, de pouca durabilidade, tornando-se rapidamente obsoletos, mediante a taxa de utilização decrescente das mercadorias) de desemprego em massa - considerado estrutural - da precarização do trabalho, no qual predominam as terceirizações e a informalidade, da corrosão dos direitos trabalhistas e sociais, do processo de mercantilização das empresas e serviços públicos e a submissão mais direta dos estados aos interesses do capital. Além do acirramento das desgraças sociais: miséria, pobreza, fome, violência e ainda a degradação dos serviços de saúde, habitação, saneamento, educação etc.

Como denuncia Antunes, na busca de respostas às demandas de sua crise o capital iniciou um processo de reorganização "de seu sistema ideológico e político de comunicação, cujos contornos mais evidentes foram o advento do neoliberalismo, com a privatização do 
Estado, a desregulamentação dos direitos trabalhistas e a desmontagem do setor produtivo estatal" (ANTUNES, 2003, p.31).

A sociedade capitalista, desde o século XIX, é regulada por orientação liberal. Atualmente, essa orientação se reveste na roupagem de neoliberalismo que, assim como as correntes liberais, têm como princípio o Estado mínimo (não-intervenção do Estado) na economia, privatização, individualismo, propriedade privada, destruição dos serviços públicos e políticas de desregulamentação do trabalho.

No Brasil, são qualificados de neoliberais os principais pontos da reforma constitucional impostos pelo representante oficial do neoliberalismo no Brasil, Fernando Henrique Cardoso, numa explicita vinculação aos ditames do chamado "Consenso de Washington", que são: ajuste fiscal; redução do tamanho do Estado; fim das restrições do capital externo (eliminar todo e qualquer empecilho ao capital especulativo ou vindo do exterior); abertura do sistema financeiro (fim das restrições para que as instituições financeiras internacionais possam atuar em igualdade de condições com as do país); desregulamentação (redução das regras governamentais para o funcionamento da economia); reestruturação do sistema previdenciário. A esses pontos contrapontos os "avanços" da Constituição de 1988 em cada matéria correspondente, os quais, no entanto, apenas consagravam (no caso de alguns direitos sociais) conquistas já em vigor pela ação do movimento operário e popular, quando não a simples defesa do capital monopolista nacional ou estrangeiro instalado no país (no caso, por exemplo, da distinção entre capital nacional e estrangeiro, das leis de reserva de mercado, etc.) (COGGIOLA, 2001, pp.41-42).

As concepções do neoliberalismo estão alicerçadas na mundialização e no fluxo de capital, com tecnologia avançada em um mundo sem fronteiras ou limites, globalizado e regido pelas agências multilaterais.

Os indivíduos são considerados, nessa lógica, como capital humano, sendo os mesmos os responsáveis pela sua própria situação social: condição econômica, emprego, estudo, formação profissional, pois, perante o mercado, o indivíduo tem o poder de decidir, sendo, portanto, responsável por sua condição na escala social vigente, considerando que a meritocracia $^{6}$ é uma prática que legitima as ações no modo de produção, competitivo, capitalista.

Noutro sentido Leher (1999, p.22) considera que

O ajuste estrutural que desmonta o precário Estado Social é feito em nome da globalização, um processo apresentado como inexorável e irresistível, contra o qual

\footnotetext{
${ }^{5}$ Williamson denominou Consenso de Washington o conjunto de recomendações saídas da reunião porque teria constatado que se tratava de pontos que gozavam de certa unanimidade, ou seja, as reformas sugeridas eram reclamadas pelos vários organismos internacionais e pelos intelectuais que atuavam nos diversos institutos de economia. (SAVIANI, 2008, p.427)

${ }^{6}$ Predominância dos que possuem méritos; predomínio das pessoas que são mais competentes, eficientes, trabalhadoras ou superiores intelectualmente, numa empresa, grupo, sociedade, trabalho etc. (DICIONÁRIO ON LINE, 2018)
} 
nada é possível fazer, a não ser se adaptar, mesmo que às custas de exponencial desemprego, privatizações selvagens, crise cambial, aumento da taxas de juros e destruição dos direitos do trabalho.

A criação de um Estado mínimo se faz necessário para a legitimação e efetivação do Neoliberalismo, no tocante à intervenção na economia e responsabilidade com as questões sociais, porém forte na empreitada pela permanência da ordem vigente, garantindo, mesmo em tempos de crise, os interesses da classe dominante.

A educação, no neoliberalismo, também está a serviço da reestruturação do capital em crise, e visa, dentre outras coisas, atender às exigências do mercado e possibilitar a formação de mão-de-obra adequada às novas exigências da acumulação do capital.

A educação é o maior instrumento para o desenvolvimento econômico e social, ela é central na estratégia do Banco Mundial para ajudar os países a reduzir a pobreza e promover níveis de vida para o crescimento sustentável e investimento no povo. Essa dupla estratégia requer a promoção do uso produtivo do trabalho (o principal bem do pobre) e proporcionar serviços sociais básicos para o pobre (BANCO MUNDIAL, apud LEHER, 1999, p.23).

Deste modo, Saviani (2008) destaca em que significado a teoria do Capital Humano ${ }^{7}$ passa a atender as demandas da crise, neste sentido “[...] é o indivíduo que terá de exercer sua capacidade de escolha visando a adquirir os meios que lhe permitam ser competitivo no mercado de trabalho"(SAVIANI, 2008 p.430), sua permanência no mesmo com mão - de obra qualificada e assim sua permanência na sociedade de forma digna e produtiva, tendo

[...] como objetivo fundamental contribuir para o aumento da produtividade e da competitividade empresariais, prioritariamente dos setores monopolistas, de capital estrangeiro. A educação superior, por sua vez, passa a ter como prioridades, a partir de então, capacitar a força de trabalho para adaptar a tecnologia produzida no exterior e conformar este novo trabalhador qualificado às novas exigências da cultura empresarial, especialmente no que tange à aceitação, como naturais das desigualdades sociais, da competição acirrada entre indivíduos, grupos e classes e da perda dos seus direitos, conquistados ao longo da história (NEVES, 2002, p. 26).

\footnotetext{
7 “Na verdade, essa teoria surgiu no período dominado pela economia Keynesiana e pela política de Estado de bem-estar, que, na chamada era de ouro do capitalismo, preconizavam o pleno emprego. Assim, a versão originária da teoria do capital humano entendia a educação como tendo por função preparar as pessoas para atuar num mercado em expansão que exigia força de trabalho educada. À escola cabia formar mão-de-obra que progressivamente seria incorporada pelo mercado, tendo em vista assegurar a competitividade das empresas e o incremento da riqueza social e da renda individual.

No entanto, após a crise de 1970, a importância da escola para o processo econômico-produtivo foi mantida, mas a teoria do capital humano assumiu novo sentido. O significado anterior estava pautado numa lógica centrada em demandas coletivas, tais como o crescimento econômico do país, a riqueza social, a competitividade das empresas e o incremento dos rendimentos dos trabalhadores. O significado que veio a prevalecer na década de 1990 deriva de uma lógica voltada para a satisfação de interesses privados, 'guiada pela ênfase nas capacidades e competências que cada pessoa deve adquirir no mercado educacional para atingir uma melhor posição no mercado de trabalho' (GENTILI, 2002, p. 51)” (SAVIANI, 2008, p. 429).
} 
A interferência do Banco Mundial na educação se faz, de forma bastante incisiva, nos países periféricos da produção capitalista. Tal influência objetiva adequar a educação ao modelo neoliberal numa perspectiva global para o aumento do capital. A educação por meio de reformas educacionais passa a ser um grande negócio para as empresas que, por sua vez, comandam e dão as diretrizes educacionais para as escolas e universidade, ou seja, a educação passa a obedecer as logicas empresariais e não uma política pública de educação oferecida pelo Estado que acaba privatizando suas instituições educacionais transformando-as em grandes empresas privadas. Assim os,

\begin{abstract}
Sistemas Educacionais Que Até Poucas Décadas Atrás Possuíam Significativa Diversidade Entre Si, Como Os Da Costa Do Marfim, De Marrocos, De Mali, Da Venezuela, Do Brasil, Da Argentina, Do Chile Etc., Estão Reconfigurando Seus Modelos Por Meio De Reformas Que Obedecem A Um Plano De Obra De Uniformidade Fastidiosa, Como Se Resultante De Um Admirável "Consenso" Que Teria Se Alastrado Pelas Regiões "Em Desenvolvimento" Na Década De 90. No Brasil, A Exemplo Dos Demais Países, As Principais Medidas Do Governo Para O Setor Estão Direcionadas Para O Ensino Elementar [...] E Para A Formação Profissional [...]. Em Comum, Todos Estão Empreendendo Reformas Curriculares, Construindo Sistemas Centralizados De Avaliação E Introduzindo Novos Recursos Tecnológicos Nas Escolas, Assim Como Medidas Para Desobrigar O Estado Dos Demais Níveis E Modalidades. O Caso Das Universidades Federais Brasileiras É Patente. Por Meio De Uma Pretensa Política De Autonomia, O Governo Cria As Condições Para Um Aprofundamento Da Privatização (LEHER, 2009, P. 2).
\end{abstract}

Considera-se oportuno analisar o caráter das ações do Banco Mundial no panorama das políticas internacionais voltadas à educação, já que o mesmo, segundo Leher (2009, p.3), “[...] representa uma estrutura material da ideologia da globalização com a função mediadora de organizar e difundir a 'concepção de mundo' que os 'senhores do mundo' querem consolidar e reproduzir, neste contexto de crise estrutural”.

Daí o Banco Mundial concluir que é preciso dinheiro privado. Considera que os quatro ou cinco anos de educação primária incumbem ao Estado, mas que a educação secundária e superior deve ser paga pelos pais. Acha também que nos países pobres, em particular os da África, é preciso diminuir o salário dos professores, para reduzir a diferença entre o que eles ganham e a renda dos camponeses (CHARLOT, 2014, p.22).

Inicialmente, o Banco Mundial não tinha interesse em investir na educação, uma vez que educação não era considerada atividade de atuação de um Banco - como disse Robert Gardner, vice-presidente do Banco Mundial na década de 1960 (CAUFIELD apud LEHER, 1999, p. 25-26), assim “Até a década de 1960, a educação era uma questão secundária para o 
Banco Mundial, considerada uma atividade marginal e dispendiosa" (LEHER, 1998, p. 202).

Porém, com a disseminação do ideário neoliberal, que teve início nos anos 1970, o Banco passa a traçar objetivos no campo educacional, logo “[...] esta concepção começou a mudar quando o Banco começou a dar ênfase ao problema da pobreza e a educação sobressaiu-se entre as prioridades do Banco" (Idem, ibidem).

A princípio, a educação era vinculada a $\mathrm{UNESCO}^{8}$, com o intuito de organizar programas de apoio ao ensino, promover o desenvolvimento científico e a repatriação com objetivos culturais do pós-guerra. Entretanto quando os Estados Unidos ${ }^{9}$ deixa a UNESCO, em 1984, a mesma perde suas funções e atribuições para o Banco Mundial. Por conseguinte, a educação mundial passa, a partir deste momento a serem comandadas como estratégia políticoeconômica, direcionada pelo Banco Mundial, para o mercado de trabalho.

\section{A Educação como Negócio e a Conferência Mundial de Educação para todos}

Na relação instituída entre o Banco Mundial e os países periféricos da produção capitalista, prioriza-se os aspectos políticos e ideológicos. Assim sendo, compreende-se, apoiados em Leher (1998), que os Bancos se beneficiam de sua condição de financiadores da educação desses países, para determinar a lógica neoliberal que torna o ensino técnico e com caráter empreendedor. E assim estabelece as regras de funcionamento e organização da educação nos países que se comprometem com esse tipo de financiamento, num claro desmonte das estruturas estatais em benefício das grandes empresas privadas.

\footnotetext{
${ }^{8}$ A UNESCO é a agência especializada da Organização das Nações Unidas (ONU) para a Educação, a Ciência e a Cultura. Foi criada em 1945, na Conferência de Londres, tendo sido basicamente uma instituição norte-americana produzida no contexto da Guerra Fria e da ideologia do desenvolvimento (PRESTON JR., et. al, 1989). Porém, contra todas as expectativas, com o processo de descolonização e o deslocamento da Guerra Fria para os países periféricos, a UNESCO foi transformada pelo Movimento dos Países Não-Alinhados e pelos países socialistas em uma referência significativa para o debate educacional, encorajando políticas que favoreceram a aprendizagem e o acesso ao conhecimento de populações até então submetidas à violência da dominação estrangeira, representando um símbolo de esperança para os países explorados e de economia deformada, além de ser um dos "organismos promotores do 'Prêmio Nacional de Referência em Gestão Escolar', instituído em 1998 e que já está se tornando um marco na avaliação e premiação da gestão escolar pública no Brasil” (SOUZA, 2001, p. 4243).

${ }^{9}$ As principais justificativas, segundo Leher (1998), para a saída dos EUA, Inglaterra e Cingapura da UNESCO, estariam no bojo do deslocamento da ideologia do desenvolvimento para a da globalização. A era do mercado ou da globalização é anunciada pelo atual presidente do Banco Mundial como a "maior transformação histórica da história recente", uma conquista duradoura, um ponto zero. "O Banco construiu as bases da política do novo século e do novo milênio" (EDWARDS, apud LEHER, 2009, p.5). Deste modo, a política do presidente Ronald Reagan dá início a era contra todos os organismos e instâncias da ONU, elevando o Banco Mundial ao papel de "Ministério da Educação dos países periféricos".
} 
Neste cenário contemporâneo de crise, as determinações oriundas da agenda do capital internacional para educação, mais especificamente formuladas a partir de 1990 pela Conferência Mundial de Educação para Todos ${ }^{10}$, realizada em Jomtien, Tailândia, patrocinada pelo Banco Mundial, podem ser consideradas como o marco na busca pelo ajuste da educação às necessidades do mercado, diante de um processo de reestruturação produtiva.

A Conferência foi o divisor de águas no tocante à educação e é, portanto, a partir dos anos de 1990, que o Brasil vem passando por várias mudanças no cenário educacional. Em 1996 tivemos a promulgação da Lei de Diretrizes e Bases da Educação Nacional - LDB 9.394 de 20 de dezembro daquele ano, pouco tempo depois foi baixado o Decreto $\mathrm{n}^{\circ} 2.208$ de 17 de abril de $1997^{11}$ - tendo sua "revogação" por meio do Decreto n 5.154 de 26 de julho de 2004 - além de outros aparatos legais de ajuste da educação às políticas neoliberais, que têm como carro chefe a privatização do ensino e a formação de capital humano para o mercado de trabalho.

Como resultado da Conferência Mundial de Educação para Todos, elaborou-se o relatório "Educação: um tesouro a descobrir", também conhecido como Relatório Delors, que apresenta como princípios "os quatro pilares da educação" e "a educação ao longo da vida". Destacamos tais princípios por entendermos que estes se constituíram como amplamente divulgados, sendo os mesmos usados como orientação para a implementação de políticas e ações para a formação dos professores e alunos.

O relatório justifica a necessidade de uma educação ao longo de toda a vida "[...] como uma das chaves de acesso ao século XXI" com a finalidade de responder "[...] ao desafio de um mundo em rápida transformação" (DELORS, 2000, p.19) exigência que já se coloca há um tempo e que continua apropriada, todavia "só ficará satisfeita quando todos aprendermos a aprender" (Idem, ibidem).

Nessa mesma orientação são elaborados os Parâmetros Curriculares Nacionais - PCNs - assumidos como política de Estado pelo $\mathrm{MEC}_{2}$ no intuito de servir de referência para a elaboração dos currículos escolares de todo país. Pois,

\footnotetext{
10 "Especialistas de todo o mundo foram convocados pela UNESCO para compor a Comissão Internacional sobre Educação para o século XXI, coordenada pelo francês Jacques Delors. Essa Comissão identificou tendências e necessidades no cenário de incertezas e hesitações que caracterizam esse final de século, enfatizando o papel que a educação deveria assumir. Produzido entre 1993 e 1996, o Relatório Delors é um documento fundamental para compreender a revisão da política educacional de vários países na atualidade" (SHIROMA et al, 2007, p.55).

11 A LDB, afinada com a política do Estado Mínimo, determinada pelos organismos internacionais, retira do Estado a obrigatoriedade de oferecer o ensino médio, entregando à iniciativa privada o ensino técnico-profissionalizante através do Decreto $\mathrm{N}^{\circ}$ 2.208/97, o qual, agudiza ainda mais o dualismo construído historicamente no sistema educacional brasileiro.
} 
As justificativas em que se apóia a defesa do "aprender a aprender", nos PCNs, são as mesmas que contam do "Relatório Jacques Delors": o alargamento do horizonte da educação que coloca para a escola exigências mais amplas. Trata-se, agora, de capacitar para adquirir novas competências e novos saberes, pois as "novas relações entre conhecimento e trabalho exigem capacidades de iniciativa e inovação e, mais de que nunca, 'aprender a aprender"” num contínuo "processo de educação permanente" (Brasil, MEC, 1997, p.34) (SAVIANI, 2008, p.433).

Assim, como denuncia Arce (2011, p. 260), baseado em novos preceitos se erguem os quatro novos pilares para a educação "fundamentados no prazer, no utilitarismo e no individualismo, encarados como investimento em Capital Humano competitivo no mercado de trabalho", balizada pelos referidos pilares, a saber:

- Aprender a conhecer, combinando uma cultura geral, suficientemente vasta, com a possibilidade de trabalhar em profundidade um pequeno número de matérias.

- Aprender a fazer, a fim de adquirir não somente uma qualificação profissional, mas, de uma maneira mais ampla, competências que tornem a pessoa apta a enfrentar numerosas situações e a trabalhar em equipes.

- Aprender a viver juntos, desenvolvendo a compreensão do outro e a percepção das interdependências - realizar projetos comuns e preparar-se para gerir conflitos - no respeito pelos valores do pluralismo, da compreensão mútua e da paz.

- Aprender a ser, para melhor desenvolver a sua personalidade e estar à altura de agir com cada vez maior capacidade de autonomia, de discernimento e de responsabilidade pessoal. Para isso, é preciso não negligenciar na educação nenhuma das potencialidades de cada indivíduo: memória, raciocínio, sentido estético, capacidades físicas. Aptidão para comunicar-se (Arce, 2001, p. 260. Grifo nosso).

Outrossim, Saviani (2008, p. 432) vem analisando a relação dos pilares com a tendência pedagógica do escolanovismo, em que o lema do "aprender a aprender" refere-se "à valorização do processo de convivência entre as crianças, do relacionamento entre elas e com os adultos, de sua adaptação à sociedade". Assim,

O lema do "aprender a aprender", tão difundido na atualidade, remete ao núcleo das ideias pedagógicas escolanovistas. Com efeito, deslocando o eixo do processo educativo do aspecto lógico para o psicológico; dos conteúdos para os métodos; dos professores para os alunos; do esforço para o interesse; da disciplina para a espontaneidade, configurando-se uma teoria pedagógica em que o mais importante não é ensinar e nem mesmo apender algo, isto é, assimilar determinados conhecimentos. O importante é aprender a aprender, isto é, aprender a estudar, a buscar conhecimento, a lidar com situações novas. E o papel do professor deixa de ser o daquele que ensina para ser o de auxiliar o aluno em seu próprio processo de aprendizagem (SAVIANI, 2008, p.431).

Podemos, portanto, afirmar que o lema do "aprender a aprender" representa estreita vinculação com as necessidades de constante atualização, reciclagem, formação necessária às 
novas exigências de adaptação a sociedade atual, em que o trabalhador precisa ampliar sua margem de empregabilidade, exigindo-se deste a "capacidade de adaptação e de aprender a aprender e a reaprender" (FONSECA, 1998, p. 307 apud SAVIANI, 2008, p. 432). Diz Saviani (2008, p. 432), que “[...] na situação atual, o 'aprender a aprender' liga-se à necessidade de constante atualização exigida pela necessidade de ampliar a esfera da empregabilidade". Conclui o autor, ao analisar Fonseca (1998), que "[...] a adaptação à sociedade atual exige novos tipos de raciocínio, o desenvolvimento da capacidade de comunicação e a recuperação de funções cognitivas deterioradas pelo trabalho de tipo puramente mecânico" (Idem, ibidem). Uma formação que garante ao futuro trabalhador a flexibilidade necessária para as novas demandas do sistema capitalista, assim a ação fundamental da escola seria a concretização da habilidade de "aprender a aprender".

\section{Considerações Finais}

O presente artigo tencionou analisar em que medida a crise contemporânea interfere na implantação de políticas educacionais na periferia do capital. Para garantir o processo de reestruturação os capitalistas recorreram às políticas neoliberais, em que se exigia um tipo de trabalhador que atendesse as novas demandas produtivas.

Nesta medida, cabe-nos considerar que a educação sofreu determinações decorrentes do processo de reestruturação do capital em crise, em que as políticas neoliberais - gestadas pelos organismos internacionais, em especial o Banco Mundial - destinaram aos países periféricos a reorganização e determinações para organização e execução das políticas educacionais, alicerçadas em paradigmas educacionais fincados em conceitos como competências, habilidades e flexibilidade - demandas necessárias ao modelo produtivo, que exige um perfil de trabalhador. Os quatro pilares para educação determinariam como se deveria ser, conviver, fazer e aprender, consubstanciado no que Saviani designa como as pedagogias do "Aprender a aprender".

Porém, diante da contradição inerente à sociedade capitalista, o espaço escolar pode se constituir como um lugar de luta a serviço dos interesses dos trabalhadores. Mesmo não sendo exclusivamente o local da transformação social - no sentido da construção de uma sociedade 
justa, emancipada e realmente livre -, o mesmo poderá contribuir com a transformação como uma importante ferramenta, na medida em que proporciona aos explorados o acesso ao conhecimento científico através da viabilização das condições para sua transmissão e assimilação. Se fizer isso, cumprirá o que Saviani (2003) denomina ser específico da atividade educativa: possibilitar aos indivíduos, através do domínio da herança histórica e cultural (conhecimento, valores, símbolos, ideias, etc.), tornar-se membro do gênero humano. A escola poderá colaborar com a transformação, quando transmite o que a classe explorada precisa para compreender o real, as relações sociais que se configuram na sociedade de classes, pois a construção da consciência e de uma leitura de realidade e de mundo tem como uma importante base o saber científico-histórico.

\section{Referências}

ANDRADE, F. A.; FLORÊNCIO, L. R. S.; FERREIRA, T. M. S.; ARANHA, F. K. B. (Orgs.) LDB 20 anos: política história e espaços educacionais. Fortaleza: Edição UFC, 2016. 467p.

ANTUNES, R. Os Sentidos do Trabalho: Ensaio Sobre a Afirmação e a Negação do Trabalho. São Paulo: Boitempo, 2003.

ANTUNES, R. Adeus ao trabalho? Ensaio sobre as metamorfoses e a centralidade do mundo do trabalho. São Paulo: Cortez-Unicamp, 1999.

ARCE, A. Compre o kit neoliberal para a educação infantil e ganhe grátis os dez passos para se tornar um professor reflexivo. Educação Sociedade. vol. 22, nº 74, p. 251-283. São Paulo, 2001. ISSN 0101-7330.

CHARLOT, Bernard. Da relação com o saber às práticas educativas 1. ed. São Paulo: Cortez, 2014. [livro eletrônico]

COGGIOLA, O. Universidade e Ciência na Crise Global. São Paulo: Edições Pulsar, 2001.

DELORS, J. (org.) Educação: um tesouro a descobrir. 4. ed. São Paulo: Cortez; Brasília, DF: MEC: UNESCO, 2000.

DICIONÁRIO ONLINE DE PORTUGUES. Meritocracia. Disponível em: https://www.dicio.com.br/meritocracia/ Acesso em: 18/07/2018. 
LEHER, R. Da Ideologia do Desenvolvimento à Ideologia da Globalização: A Educação como estratégia do Banco Mundial para o "Alívio" da Pobreza. Tese de Doutorado. SP, USP, 1998.

LEHER, R. Um Novo Senhor da Educação? A política Educacional do Banco Mundial para a periferia do capitalismo. Revista Outubro. São Paulo, nº 03, 1999.

LEHER, R. Políticas de educação para a América Latina: O Bird e as reformas neoliberais na educação. Debate. Disponível em http://www.apropucsp.org.br/revista/r05_r03.htm Acesso em 06/02/2009.

MÉSZÁROS, I. A crise estrutural do capital. Revista Outubro. São Paulo, nº 04, 2000.

NEVES, L. M. W. (org.) O empresariamento da educação: novos contornos do ensino superior no Brasil dos anos 1990. In Política neoliberal e educação superior. São Paulo: Xamã, 2002.

SAVIANI, D. História das idéias pedagógicas no Brasil. 2. ed. rev. e ampl. Campinas, SP: Autores Associados, 2008. - (Coleção memória da educação)

SHIROMA, E. O.; MORAES, M. C. M.; EVANGELISTA, O. (Orgs.) Política educacional. 4. ed., Rio de Janeiro: Lamparina, 2007.

SOUZA, S. A. Gestão escolar compartilhada: democracia ou descompromisso? São Paulo: Xamã, 2001.

TONET, I. A Educação Numa Encruzilhada. In: MENEZES, Ana Maria DORTA; FIGUEIREDO, Fábio FONSECA (Orgs.). Trabalho, Sociabilidade e Educação: Uma Crítica à Ordem do Capital. Fortaleza: Ed. UFC, 2003.

UNESCO. Educação da UNESCO para a América Latina e Caribe. Santiago, 1998.

Como citar este artigo (Formato ABNT):

SINDEAUX , Rebeca Baia; BEZERRA, Francisco Wellery G.; LOUREIRO, Maria Dulcinea S. As Políticas Educacionais e a Interface Neoliberal: a educação como um tesouro a descobrir. Id on Line Rev.Mult. Psic., 2018, vol.12, n.41, p.859-871. ISSN: 1981-1179.

Recebido: 11/07/2018.

Aceito: $27 / 07 / 2018$ 